\title{
PROFIL KETERAMPILAN BERPIKIR KREATIF SISWA KELAS VII SMP NEGERI 6 SURABAYA
}

\author{
Fedela Leta maliki ${ }^{1)}$, Wahono Widodo' ${ }^{2)}$, Raharjo ${ }^{3)}$ \\ ${ }^{1)}$ Mahasiswa Program Studi Pendidikan Sains, Program Pascasarjana Universitas Negeri Surabaya \\ ${ }^{2), 3)}$ Dosen Pascasarjana Prodi Pendidikan Sains Univesrtitas Negeri Surabaya \\ E-mail:nenk.felema88@gmail.com
}

\begin{abstract}
The purpose of this research is to describe the profile of students creative thinking skill at VII grade in SMPN 6 Surabaya. This research is a descriptive research whose 30 subject. Data obtained from testing showed that the students' creative thinking skill in design an experiment reached medium N-Gain level $(0,56)$. The average N-Gain score of students' creative thinking skill based on fluency $(0,49)$; flexibility $(0,70)$; quality $(0,54)$, elaboration $(0,63)$, and originality $(0,51)$ in medium level for each aspect. Overall, it can be concluded that Learning Cycle 5E Model package is effective to increase junior high school students' creative thinking skill.
\end{abstract}

Keywords: Creative Thinking Skills, Learning Cycle 5E Model.

Abstrak Penelitian ini bertujuan untuk mendeskripsikan profil keterampilan berpikir kreatif siswa kelas VII SMP Negeri 6 Surabaya. Penelitian ini merupakan penelitian deskriptif dengan subjek 30 siswa. Data yang diperoleh menunjukkan bahwa keterampilan berpikir kreatif siswa dalam merancang kegiatan penyelidikan mencapai N-Gain 0,56 atau termasuk kategori sedang. Rata-rata nilai gain keterampilan berpikir kreatif siswa berdasarkan aspek fluency sebesar 0,49, quality sebesar 0,54, elaboration sebesar 0,63, dan originality sebesar 0,51 dengan kategori sedang pada masing-masing aspek, dan flexibility sebesar 0,70 dengan kategori tinggi. Dengan,demikian, dapat disimpulkan bahwa perangkat pembelajaran model Learning Cycle 5E ini efektif untuk meningkatkan keterampilan berpikir kreatif siswa SMP.

Kata Kunci: Keterampilan Berpikir Kreatif, Model Learning Cycle 5E

\section{PENDAHULUAN}

Keterampilan berpikir tingkat tinggi atau biasa disebut dengan singkatan HOTS (High Order Thinking Skills) merupakan salah satu keterampilan di abad ke 21 yang terus dikembangkan. Terdapat dua keterampilan dalam HOTS, yaitu keterampilan berpikir kreatif dan keterampilan berpikir kritis. Di Indonesia, melalui Kurikulum 2013 keterampilan berpikir kreatif merupakan salah satu keterampilan yang harus dikuasi siswa selain materi isi yang merupakan pemahaman konsep. Di Hong Kong, keterampilan berpikir kreatif merupakan salah satu dari tiga keterampilan yang paling menonjol untuk dikembangkan secara terpadu pada semua mata pelajaran (Curriculum Development Council, 2002). Di beberapa negara Asia yang lain juga mengubah kurikulum pendidikannya untuk menekankan pentingnya meningkatkan keterampilan berpikir kreatif (Cheng, 2011). Dengan demikian banyak negara-negara maju di dunia yang mempersiapkan siswanya tidak hanya secara akademik pada prestasi saja tetapi juga keterampilan yang dibutuhkan dalam lingkungan kerja di abad ke XXI

Di bidang teknologi dan perkembangan ilmiah, berpikir kreatif adalah komponen kritis, keterampilan manusia, dan keterampilan berpikir kreatif juga sebagai kunci penelitian (Robinson, 2001). Saat ini, di bidang pendidikan keterampilan berpikir kreatif sebagai literasi (Robinson, 2006) dan perlu dimasukkan juga sebagai dasar kecakapan hidup (Craft, 1999) yang dapat menjadikan generasi selanjutnya bertahan hidup dan berkembang di abad ke XXI (Parkhurst, 1991). Rao (2009) menambahkan bahwa keterampilan berpikir kreatif sangatlah perlu dikembangkan pada anak-anak di sekolah. Sejalan dengan hal ini, Ervynck (1991) menyatakan bahwa keterampilan berpikir kreatif memainkan peranan penting dalam siklus penuh dalam berpikir matematis.

Berpikir kreatif didefinisikan sebagai "keterampilan mental berdasarkan proses kognitif dan motivasi yang juga peranan penting dalam menginspirasi, mengimajinasi, dan mengintuisi (Purcha, Walterova \& Mares, 1998). Keterampilan ini dikembangkan sendiri dengan menemukan solusi yang tidak hanya benar, tetapi juga baru, tidak biasa, dan tidak terduga."

Menurut Skalkova (1999) dan Smekal (2004), berpikir kreatif adalah memecahkan masalah pada situasi dimana solusinya tidak jelas atau tidak dapat dipakai. Dalam memecahkannya perlu mengidentifikasi masalah secara sistematis untuk mencari solusi dan digunakan untuk mengujinya secara sistematis atau 
memilih prosedur analisis yang paling tepat dari masalah dan kondisi yang diberikan.

Zak (2004) mendefinisikan berpikir kreatif sebagai:

(1) Keterampilan, untuk mengimajinasi atau menemukan ide yang baru namun tidak berarti menciptakannya, menemukan solusi, menggunakan kombinasi, mengubah, dan mengulang ide yang sudah ada; (2) Pendekatan karakteristik secara individu, dengan menyetujui, menerima perubahan dan kebaharuan, kesediaan untuk menuangkan ide dan pemikiran; dan fleksibilitas pada pandangan.

Berdasarkan beberapa pendapat di atas penulis dapat menyimpulkan bahwa berpikir kreatif adalah keterampilan berpikir untuk membentuk gagasan atau ide baru untuk memperoleh suatu produk yang memiliki nilai kejelasan, keberagaman, kebaharuan (minimal ada modifikasi dari yang sudah ada), kebermanfaatan, serta sesuai dengan kriteria pertanyaan.

Keterampilan berpikir kreatif dapat dipandang dari sisi proses dan sisi produknya. Dipandang dari sisi proses, keterampilan berpikir kreatif merupakan respons siswa dalam menyelesaikan masalah dengan menggunakan metode yang sesuai. Dalam penelitian ini, proses keterampilan berpikir kreatif dimulai dari siswa mengetahui adanya permasalahan, merancang desain, melakukan kegiatan penyelidikan, sampai mengkomunikasikan hasil pemikirannya. Dipandang sebagai produk atau hasil, Filsaime (2008) menyatakan keterampilan berpikir kreatif adalah proses berpikir yang menekankan dan memiliki ciri-ciri kelancaran (fluency), keluwesan (flexibility), keaslian (originality) dan elaborasi (elaboration).

Kelancaran (fluency) adalah keterampilan mengeluarkan ide atau gagasan yang benar sebanyak mungkin secara jelas dan relevan. Keluwesan (flexibility) adalah keterampilan untuk mengeluarkan banyak ide atau gagasan yang beragam dan tidak monoton dengan melihat dari berbagai sudut pandang. Originalitas (originality) adalah keterampilan untuk mengeluarkan ide atau gagasan yang unik dan tidak biasanya, misalnya yang berbeda dari yang ada di buku atau berbeda dari pendapat orang lain. Elaborasi (elaboration) adalah keterampilan untuk menjelaskan faktor-faktor ini yang mempengaruhi dan menambah detail dari ide atau gagasannya sehingga lebih bernilai.

Pada penelitian ini, ada lima aspek dalam penilaian instrumen penilaian keterampilan berpikir kreatif, yaitu: kelancaran (fluency), keluwesan (flexibility), keaslian (originality), elaborasi (elaboration), dan kualitas (Quality).

Mengukur keterampilan berpikir kreatif adalah hal yang perlu dilakukan. Beberapa peneliti menggunakan tes berpikir kreatif seperti TTCT (Torrance Test of Creative Thinking), CAMT (Creative Ability in Mathematical Test), Guilford Alternative Uses Task dan alat ukur lainnya, sedangkan Getzel dan Jackson menggunakan tugas yang mempunyai banyak jawaban atau banyak cara penyelesaian (Silver, 1997).

Menurut Booth (1996), inti tes kreatif adalah tes yang memberikan kepada siswa untuk memikirkan cara/hal baru. Seperti diminta membuat karangan dengan memberikan silly sentence, meminta menjelaskan kata-kata yang di garis bawahi dalam satu kalimat, menggunakan teknik pingpong dengan saling melempar gagasan, dengan teknik hitch-hiking yakni mengambil satu gagasan yang lain, ada modifikasi dan bukan sekedar mengkopi.

Dalam penelitian ini, siswa diminta untuk merancang dan menyelidiki kegiatan penyelidikan yang akan dilakukan. Melalui merancang dan melakukan kegiatan penyelidikan ini, diharapkan dapat meningkatkan keterampilan berpikir kreatif siswa.

\section{METODE PENELITIAN}

Penelitian ini merupakan penelitian deskriptif. Populasi dari penelitian ini adalah seluruh siswa kelas VII SMPN 6 Surabaya. Sampel diambil dengan teknik Cluster Random Sampling yaitu 30 siswa kelas VII E. Data keterampilan berpikir kreatif siswa yang diperoleh berdasarkan instrumen keterampilan berpikir kreatif kemudian dianalisis sesuai dengan rubrik terlampir. Instrument ini diberikan sebanyak dua kali, yaitu pretest dan posttest dengan indikator yang sama.

Reliabilitas instrumen keterampilan berpikir kreatif siswa dengan soal bentuk uraian dihitung menggunakan rumus alpha. Hasil pretest dan posttest kemudian diuji beda untuk mengetahui adanya signifikansi dalam perbedaan hasil pretest dan posttest. Sebelum diuji beda, sampel diuji normalitasnya menggunakan uji Lilliefors. Sedangkan uji beda yang dilakukan dengan rumus uji-t untuk mengetahui adanya signifikansi dalam perbedaan hasil pretest dan posttest. Dan untuk mengetahui kategori peningkatan hasil pretest dan posttest dari keterampilan berpikir kreatif dihitung dengan menghitung rata-rata $\mathrm{N}$-Gain menggunakan rumus dari Hake (1998).

Data yang diperoleh dari instrumen keterampilan berpikir kreatif yang telah diberikan pada siswa kemudian dianalisis secara deskriptif kuantitatif dalam bentuk diagram dan persentase. Variable-variabel yang diamati dalam penelitian ini Efektivitas perangkat pembelajaran yang ditinjau dari keterampilan berpikir kreatif siswa.

\section{HASIL PENELITIAN DAN DISKUSI}

Setelah diimplementasikan dalam kelas, terlebih dahulu dilakukan uji reliabilitas, uji normalitas dan uji signifikansi perbedaan nilai pretest dan posttest yang diperoleh. Perhitungan reliabilitas instrumen menggunakan rumus belah dua ganjil-genap 
menunjukkan r11 hasil perhitungan sebesar 0,411 dan dari tabel $\mathrm{r}$ product moment diketahui rtabel dengan taraf signifikansi 0,05 dan $\mathrm{N}=30$ sebesar 0,361 . Dengan demikian dapat dikatakan instrumen keterampilan berpikir kreatif ini reliable.

Uji normalitas dihitung menggunakan uji Lilliefors. Dari hasil uji Lilliefors didapatkan $\mathrm{L}_{0}$ sebesar 0,151 dan dari tabel nilai kritis $\mathrm{L}$ didapatkan nilai $\mathrm{L}_{\text {tabel }}$ dengan taraf signifikansi 0,05 dan $\mathrm{n}=30$ sebesar 0,161 . Dengan demikian, sampel dikatakan normal karena $\mathrm{L}_{0}$ hasil perhitungan lebih kecil daripada $\mathrm{L}_{\text {tabel. }}$. Sedangkan dari hasil uji signifikansi perbedaan nilai pretest dan posttest menggunakan uji $\mathrm{t}$ didapatkan hasil $\mathrm{t}_{\text {hitung }}$ sebesar 14.08 dan dari tabel distribusi $t$ diketahui nilai dengan taraf signifikansi 0,05 dan d.b $=\mathrm{N}-1=29$ sebesar 2,46. Dengan demikian perbedaan antara hasil pretest dan posttest dikatakan signifikan

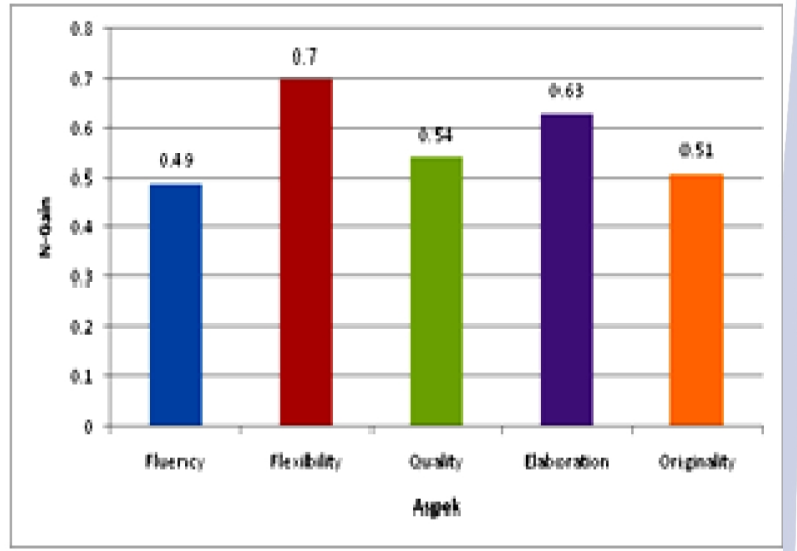

Gambar 1. Diagram Batang N-Gain Tiap Aspek Keterampilan Berpikir Kreatif Siswa

Data yang diperoleh dari Gambar 1. menunjukkan bahwa instrumen tes keterampilan berpikir kreatif siswa (LP4) yang diujikan mengalami peningkatan nilai aspek fluency, flexibility, originality, elaboration, dan quality relatif sedang, yaitu berkisar 0,49 sampai $0,70(0,4$ sampai 0,7), dengan rincian aspek fluency sebesar 0,49, flexibility sebesar 0,70, quality sebesar 0,54, elaboration sebesar 0,63, dan originality sebesar 0,51.

Peningkatan nilai pada aspek berpikir kreatif terendah adalah aspek fluency. Dalam keterampilan berpikir kreatif, aspek fluency memang paling sulit dicapai. Menurut Filsaime (2008), aspek Kelancaran (fluency) adalah keterampilan mengeluarkan ide atau gagasan yang benar sebanyak mungkin secara jelas dan relevan. Aspek fluency perlu dilatihkan secara terusmenerus untuk mendapatkan keberagaman ide atau gagasan yang jelas dan relevan. Demikian halnya dengan aspek fluency, elaboration, originality, dan quality, yang mencapai peningkatan sedang. Hal ini disebabkan selama ini siswa belum dibiasakan untuk berpikir secara kreatif.

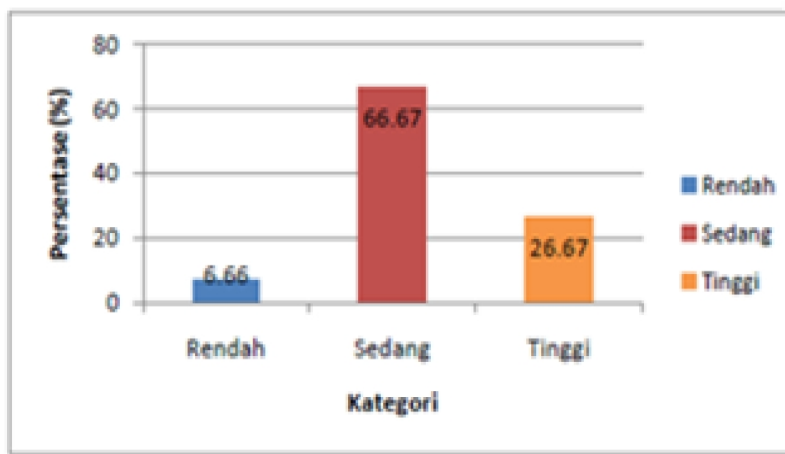

Gambar 2. Persentase N-Gain Keterampilan Berpikir Kreatif Siswa

Gambar 1 juga menunjukkan bahwa secara umum penguasaan aspek keterampilan berpikir kreatif siswa ada peningkatan dengan kategori tinggi pada aspek flexibility dan kategori sedang pada aspek fluency, elaboration, quality, dan originality setelah melaksanakan pembelajaran dengan menggunakan perangkat pembelajaran model Learning Cycle 5E yang telah dikembangkan dengan kategori sedang.

Sedangkan pada Gambar 2, sebagian besar siswa mengalami peningkatan N-Gain nilai pret-test terhadap post-test pada kategori sedang. Sebanyak 6,66\% siswa dengan kategori rendah, 66,67\% siswa dengan kategori sedang, dan 26,67\% siswa dengan kategori tinggi. Adanya peningkatan dengan kategori sedang ini juga didukung dengan model pembelajaran yang digunakan, yaitu dengan mengimplementasikan model learning cycle 5E. Liewellyn (2005) menyatakan bahwa Model Learning Cycle $5 \mathrm{E}$ adalah salah satu dari implikasi model pembelajaran konstruktivis. Model ini didasarkan pada model Learning Cycle. Learning Cycle dikembangkan pada tahun 1960-an oleh Robert Karplus (Karplus, 1980) sebagai salah satu model yang mencerminkan pembelajaran inkuiri pada mata pelajaran IPA sebagaimana yang tertuang dalam Permendikbud nomor 58 Tahun 2014.

Meningkatnya keterampilan berpikir kreatif siswa ini sesuai dengan hasil penelitian terdahulu yang dilakukan oleh Akcay and Bihey (2013) yang berjudul "Entomology: Promoting Creativity in the Science Lab" menunjukkan bahwa dengan menerapkan model Learning Cycle 5E memberi kesempatan pada siswa untuk berpikir lebih kreatif tentang perbedaan dari serangga melalui rancangan yang telah dibuat.

Penelitian yang dilakukan olek Kleiman (2008) dengan judul "Toward transformation: Comception of creativity in higher education" menunjukkan bahwa keterampilan berpikir kreatif dapat dihubungkan dengan banyak domain dengan batasan dalam melatihkan sifat dan karakter secara personal, motivasi diri, resiko pengambilan keputusan, kepercayaan diri, rasa ingin 
tahu, perhatian secara detail, sikap individu, kesabaran, dan keterampilan untuk mengatasi kelengangan.

Department for Children, Schools, and Families of UK (2008) menyatakan bahwa setiap orang mampu berpikir kreatif pada lingkungan aktivitas yang berbedabeda bila kondisinya tepat dan siswa mempunyai pengetahuan dan keterampilan yang relevan. Wilks (Ergin, 2012) menunjukkan bahwa keterampilan berpikir tingkat tinggi, dalam hal ini keterampilan berfikir kreatif siswa, dapat diajarkan dan dilatihkan pada semua siswa. Dengan demikian model Learning Cycle 5E dapat digunakan sebagai fasilitas dalam meningkatkan keterampilan berpikir kreatif siswa.

\section{KESIMPULAN}

\section{A. Simpulan}

Berdasarkan hasil dan pembahasan di atas, maka dapat disimpulkan bahwa pembelajaran IPA dengan perangkat pembelajaran model Learning Cycle 5E pada materi kalor dan perubahannya yang telah dikembangkan efektif dan layak digunakan untuk mengembangkan keterampilan berpikir kreatif siswa.

\section{B. Saran}

Berdasarkan hasil dann pembahasan di atas, peneliti memberikan beberapa saran untuk menjelaskan tentang prosedur keselamatan kerja terhadap alat dan bahan yang akan digunakan dalam melakukan kegiatan penyelidikan, terutama pada materi kalor dan perpindahannya, kelistrikan, metode ilmiah, dan lainlain

\section{DAFTAR PUSTAKA}

Akcay \& Behiye. (2013). Entomology: Promoting Creativity in the Science Lab. Science Activities: Classroom Projects and Curriculum Ideas, v50 n2 p49-53

Booth, V. H. (1996). Creativity test, arts, and activities. Journal: Sep 1996. Vol. 120, Iss. 1; pg. $23,3$.

Cheng, V. (2011). Infusing creativity into Eastern classrooms: Evaluations from student perspectives. Thinking Skills and Creativity, 6 , 67-87.

Craft, A. (1999). Creative development in the early years: some implications of policy for practice. Curriculum journal, 10(1), 135-150.

Curriculum Development Council (2002). Basic education curriculum guide: Building on strengths (primary 1-secondary 3). Hong Kong: The Education Department, HKSAR Government.

Departement for Children, Schools, and Families of UK. (2008). Developing Ctitical and Creative Thinking in Science. London: Departement of Education
Direktorat Jendral Managemen Pendidikan Dasar dan Menengah, Kemendikbud. (2014). Peraturan Menteri Pendidikan dan Kebudayaan Nomor 104Tahun 2014 tentang Penilaian Hasil Belajar oleh Pendidik pada Pendidikan Dasar dan Pendidikan Menengah. Jakarta: Kemendikbud.

Ergin, I. (2012). "Constructivist Approach Based 5E Model and Usability Instructional Physics:. Latin American Journal of Physics Education Vol. 6 No. 1, pp. 14-20

Ervynck, G. (1991). Mathematical Creativity. In D. Tall (Ed), Advanced Mathematical Thinking, 4253. Dordrecht, the Netherlands: Kluwer Academic Publisher

Filsaime, D. K. (2008). Menguak Rahasia Berpikir kritis dan kreatif. jakarta: Prestasi Pustaka.

Le Metais, J. (2003). International trends in curriculum frameworks. Educational Forum, 67(3), 235247.

Karplus, R. (1980). Teaching for the Development of Reasoning in Science Education International Report. The Ohio State University

Kleiman, P. (2008). Toward transformation: Comception of creativity in higher education. Innovation in Education and Teaching International. 45, 209-217.

Hake, R. R. (1998). Interactive-Engagement Versus Traditional Methods: A Six-Thousand-Student Survey Of Mechanics Tes Data For Introductory Physics Course, Am. J. Physics. American Association of Physics Teachers 66 (1) 64-74.

Parkhurst, H. (1999). Confusion, lack of consensus, and the definition of creativity as a construct. Journal of Creative Behaviour, 33, 1-21

Prucha, J., Walterova, E., \& Mares, J. (1998). Pedagogický slovník. Praha: Portál

Robinson, K. (2006). Do schools kill creativity? In Presentation at TED2006 conference, Monterey, CA.

Robinson, K. (2001). Out of Our Minds: Learning to Be Creative. John Wiley \& Sons.

Savinainen, S. \& Scott, P. (2002). "The Force Concept Inventory. ATool for Monitoring Student Learning:. Journal of Physics Education. 37 (1): $45-52$

Skalkova, J. (1999). Obecná didaktika. Praha: ISV. Science Education International 18

Smekal, V. (2004). Pozvání do světa osobnosti: člověk v zrcadle vědomí a jednání. Brno: Barrister \& Principal

Zak, P. (2004). Kreativitas její rozvoj. Brno: Computer Press 